NECROLOGIE

\title{
Gino Luzzatto
}

Le 30 mars 1964, mourait à Venise Gino Luzzatta, dans sa quatre-vingtsixième année, après une longue vie de travaux marqués par une intelligence claire et aiguë. L'Italie a perdu avec lui l'un des plus grands, l'un de ses plus authentiques historiens.

Sa position au milieu des vicissitudes politiques aura été indépendante, sereine, bien qu'il ait milité de façon active dans les rangs de la gauche démocratique italienne. Ferme et courageuse aura été également son attitude à l'égard du fascisme : ce qui lui valut la prison. Il ne se départit pas de son calme, même après la promulgation des lois raciales contre les Juifs, qui l'obligèrent à quitter Venise et son enseignement pour entrer dans la vie errante de la clandestinité.

Son ouvre de savant révèle un équilibre extraordinaire, qu'on a pu qualifier d" "olympien ". Elle est centrée sur l'histoire économique de l'Europe, dont il a été l'un des pionniers : en particulier, dans le cadre de l'histoire vénitienne, qui s'élargit si aisément au monde italien et à l'Occident dans leur entier, depuis le Moyen Age jusqu'à nos jours. Gino Luzzatto poursuivit ses travaux, toujours attentif aux nouvelles orientations du métier d'historien, tout en se refusant à céder aux modes. Il s'appuyait sur une solide base documentaire, mais demeurait critique a l'égard de ses sources, ne leur demandait pas plus qu'elles ne pouvaient réellement donner.

Cette attitude sereine et détachée, il l'a gardée aussi devant la mort. Il était assez gravement malade depuis longtemps : néanmoins il ne céda pas aux exigences de la maladie. Jusqu'au dernier jour, il demeura à la tache; il était en train, en effet, de revoir les pages rédigées pour le deuxième volume de l'Histoire économique de l'Italie. Jusqu'au bout, il a continué à correspondre avec ses amis politiques. Il ne renonça pas même au plaisir de rester en contact immédiat avec la ville qu'il aimait : dans les tout derniers jours, il avait parcouru à pied le quartier de Rialto, où il venait de transférer sa demeure, et s'était rendu en bateau jusqu'à la place Saint-Marc. Le soir du 29 mars, il s'attarda à contempler de ses fenêtres les lumières du Grand Canal qui s'éteignaient dans la nuit. Puis, jusqu'à une heure très tardive, il écouta à la radio la transmission d'une ouvre de Mozart. Cette même nuit, tandis qu'il écoutait la musique, étendu sur son lit, une dernière crise cardiaque le terrassa.

Depuis une trentaine d'années, il était connu en France, ayant été l'un des premiers collaborateurs étrangers des Annales de Marc Bloch et de Lucien Febvre. A l'occasion de sa mort, la Nuova Rivista Storica (qu'il dirigea pen- 


\section{A N N A L ES}

dant de très nombreuses années) lui a consacré un numéro spécial (fasc. I-II, t. XLIX, janvier-avril 1965), où Angelo Tursi a dressé la Bibliographie de ses travaux (pp. 185-211).

G. Cozzi.

\section{Friedrich Lütge}

Friedrich Lütge est mort le 25 août 1968, après une longue et douloureuse maladie, à l'áge de soixante-six ans. Il n'avait quitté que peu de mois auparavant sa chaire d'histoire économique et sociale à l'université de Munich. Pour qui l'a fréquenté dans les derniers mois de son existence en d'amicales discussions scientifiques ou de joyeux propos de table, ce décès est apparu comme particulièrement brutal, tant Lütge, jusqu'au bout, respirait l'activité et l'énergie.

Fils d'un capitaine au long cours, frère d'un émigrant qui fit en Argentine une carrière d'historien, Lütge est originaire de la région du Harz. Né à Wernigerode en 1901, il commença ses études après la Première Guerre mondiale, passant d'une université à l'autre, comme il était alors d'usage en Allemagne. D'abord à Freiburg où il suivit les cours de Georg von Below, coéditeur de Vierteljahrschrift für Sozial- und Wirtschaftsgeschichte, puis à Marburg et à Iéna, où Franz Gutmann, de l'école de G. F. Knapp et W. Wittich, lui donna son sujet de thèse : la libération des paysans dans le comté de Wernigerode. Devenu "Dr. rer. pol. "en 1924, il passa plusieurs années dans la maison d'édition Gustav Fischer à Iéna, afin d'écrire l'histoire de cette maison qui, ces années-là, commençait la publication de la grande entreprise de Georg Brodnitz, Handbuch der Wirtschaftsgeschichte. En même temps, en 1928, il terminait chez G. Menz, de la faculté de lettres, une autre thèse sur l'histoire du commerce des livres à Iéna.

Lecteur de la maison Fischer pendant plusieurs années, Lütge se consacra alors à des questions de politique sociale. Mais son intérêt profond pour l'histoire économique prévalut : se conformant aux traditions de la Historische Schule sur l'économie politique allemande, ses recherches s'orientèrent vers les problèmes d'organisation agraire ("Agrarverfassung "). De la "Libération des paysans dans le comté de Wernigerode", il passa à l'étude de la "Grundherrschaft "dans la région dont la Thuringe était le centre; il découvrait là un nouveau type de régime foncier, différent de celui décrit par Knapp pour l'Allemagne du sud-ouest, et aussi de celui observé par Wittich dans l'Allemagne du nord-ouest : la Thuringe n'aurait connu aucune forme de servage, mais seulement des charges réelles ("Reallasten "). Après avoir publié, en 1934, le livre intitulé Die mitteldeutsche Grundherrschaft (réédité en 1957, avec un chapitre sur la disparition de ce régime des terres), Lütge entreprit 